\title{
Research on the Crash Safety of the Car Bumper Base on the Different Standards
}

\author{
Q. H. Ma ${ }^{1}$, C. Y. Zhang ${ }^{2,}$ S. Y. Han ${ }^{3}$ and Z. T. Qin ${ }^{4}$ \\ ${ }^{1}$ Shanghai Univ Engn Sci, college of automotive engineering, \\ Shanghai 201620, Peoples R China \\ ${ }^{2}$ Shanghai Univ Engn Sci, college of mechanical engineering \\ Shanghai 201620, Peoples R China \\ ${ }^{3}$ Shanghai Univ Engn Sci, college of automotive engineering, \\ Shanghai 201620, Peoples R China \\ 4Shanghai Univ Engn Sci, college of automotive engineering, \\ Shanghai 201620, Peoples R China \\ 1mqh0386@163.com,2keke204102@163.com, \\ 3chsy901126@126.com,4771973382@qq.com
}

\begin{abstract}
The bumper is an important part of a vehicle safety performance evaluation. In this paper, a domestic A-class car bumper as the object of study.CAE model was established by using HyperMesh software, and the finite element method is applied to solve the calculation of the model. The bumper were studied in C-NCAP and E.C.E R42 two different standards. The bumper is optimized by changing the structure size of the way. Appropriate to increase the thickness of the metal bar bumper can improve its safety performance, while its weight changed little.
\end{abstract}

Keywords: Automotive engineering, bumper, CAE model, HyperMesh pre-treatment, finite element analysis

\section{Introduction}

With the rapid development of auto industry, traffic accident rate is higher and higher; all countries begin to attach importance to the vehicle safety. Research on the safety of bumper collision has large help to improve the vehicle collision safety, so the bumper safety performance has important significance. In the early 1930s Europe has began studying the vehicle collision at that time, the main research method is experimental method [1]. After the $1980 \mathrm{~s}$ with the development of the computer, the vehicle collision research method change into the finite element method, for example, Pickett. A.K et al., using the finite element method to evaluate the bus collision resistance performance, they have optimized and improved its structure [2-4]. Today, the finite element analysis method has become the main method of the research on vehicle collision, so this article will be in accordance with the steps of the finite element method study, starting from establishing the CAE model, to obtained the solution and analysis the method by using Ls-dyna and HyperMesh software and analysis, finally put forward the optimization suggestions to, provides the reference for bumper impact study. 


\section{CAE model}

CAE model is set according to the C - NCAP100 \% positive collision regulations, the class A vapor bumper size for long: $1130 \mathrm{~mm}$, width: $65 \mathrm{~mm}$, high: $110 \mathrm{~mm}$, thickness: $2.2 \mathrm{~mm}$. Can suck box for long: $140 \mathrm{~mm}$, width: $65 \mathrm{~mm}$, high: $85 \mathrm{~mm}$. Material is low carbon steel, and crash box has no guide groove. Figure 1 is the A-class car bumper collision CAD model. Including bumper, crash box, and simulation of vehicle plate rigid wall.

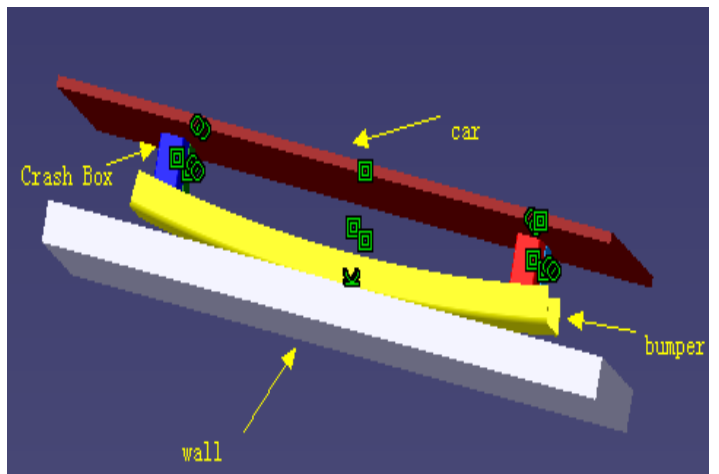

Figure 1. A-class Car Bumper Collision CAD Model

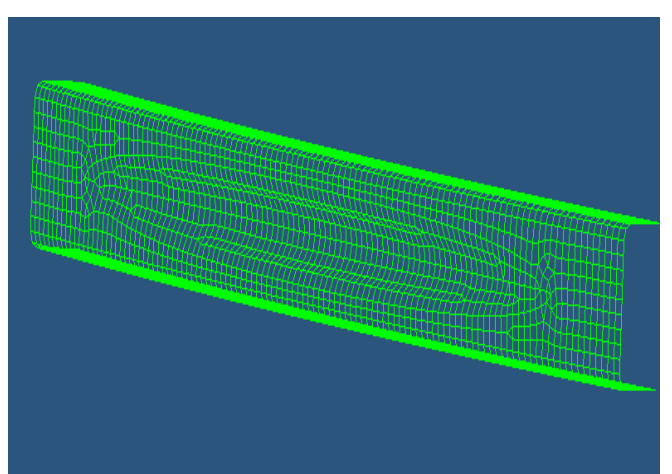

Figure 2. A -class Car Bumper CAE Model

\section{Finite Element Calculation Parameters Settings}

\subsection{Model Material Settings}

The a-class car bumper materials is mainly for low carbon steel, the material Number is MAT24 in HyperMesh. Main properties such as Table 1.

Table 1. Bumper Material Properties

\begin{tabular}{ccccc}
\hline $\begin{array}{c}\text { Material } \\
\text { number }\end{array}$ & $\begin{array}{c}\text { density } \rho \\
\mathrm{kg} / \mathrm{m}^{3}\end{array}$ & $\begin{array}{c}\text { yield } \\
\text { strength } \\
\mathrm{MP}_{\mathrm{a}}\end{array}$ & $\begin{array}{c}\text { Young's } \\
\text { modulus } \\
\mathrm{P}_{\mathrm{a}}\end{array}$ & $\begin{array}{c}\text { Poisson's ratio } \\
\lambda\end{array}$ \\
\hline MAT24 & 7.9 & 382 & 210000 & 0.3 \\
\hline
\end{tabular}

\subsection{Model Properties Option}

Bumper belongs to the structure of thin shell monomer, so choose shell unit as the bumper CAE model properties, and shell unit is more facilitate to the division of the grid and calculation, especially for automobile bumper collision that be widely used are widely used in the study of automobile collision

\subsection{Speed, Contact and Weight Settings}

Research based on the C - NCAP100 \% head-on collision regulations as standard, the standard frontal crash is not lower than the speed of $50 \mathrm{~km} / \mathrm{h}$. So the speed is $50 \mathrm{~km} / \mathrm{h}$ in this study. Because of the $100 \%$ positive collision , contact Settings is available in contact with the surface. The A-class car net empty weight to total weight is $1325 \mathrm{~kg}$, maximum safe load is $1660 \mathrm{~kg}$, so plate on each node weight is $230 \mathrm{~g}$ for the CAE model in the simulation of the vehicle, total weight is $1458 \mathrm{~kg}$ in line with the actual situation. 


\section{The Results Analysis and Optimization}

\subsection{The Bumper Cloud Image Analysis}

The a-class car bumpers add speed change in the collision process is shown in Figure 3, figure in a - $\mathrm{f}$ is the whole cloud picture of collision bumper acceleration, in the process of contact with rigid wall can be found, the bumper acceleration began to increase, and began to spread as the collision, in both sides of the bumper front arc in the surface in combination with maximum acceleration. According to the numerical value of cloud picture can see clearly in the collision in the process of the minimum acceleration is zero and the meaning is the bumper is not contact with the rigid wall, the maximum acceleration of $952.3 \mathrm{~m} / \mathrm{s} 2$ is around $97.17 \mathrm{~g}$.

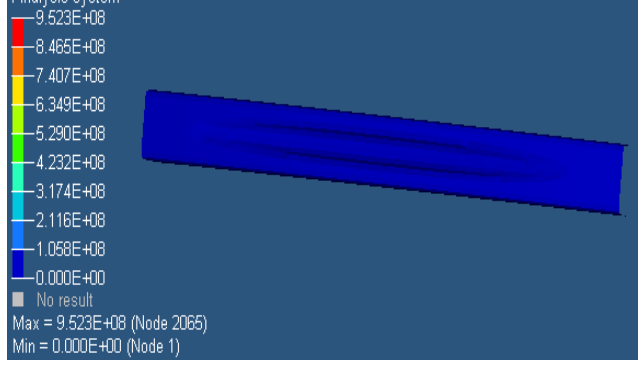

\section{a. Before the Collision Bumper Acceleration}

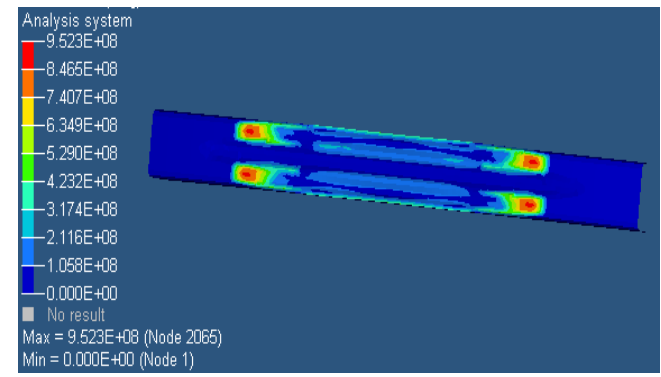

\section{c. Bumper Acceleration in Collision}

$\mathrm{t}=4 \mathrm{~ms}$

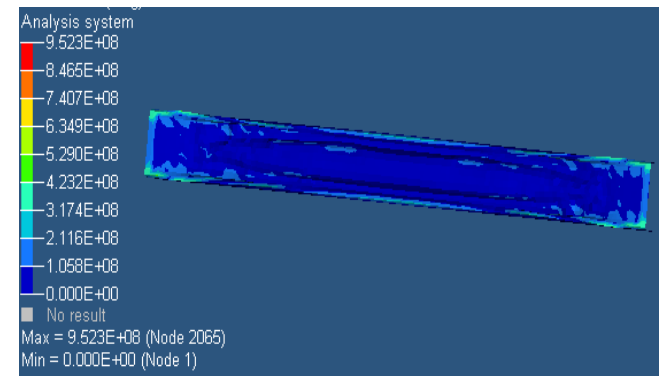

e. Bumper Acceleration in Collision $\mathrm{t}=6 \mathrm{~ms}$

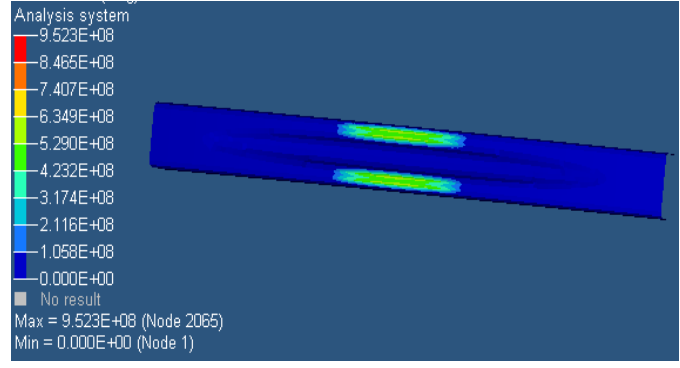

b. Bumper Acceleration in Collision

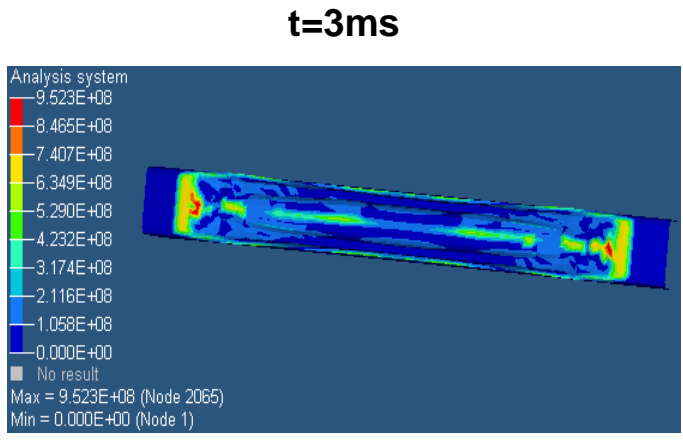

d. Bumper Acceleration in Collision $t=5 \mathrm{~ms}$

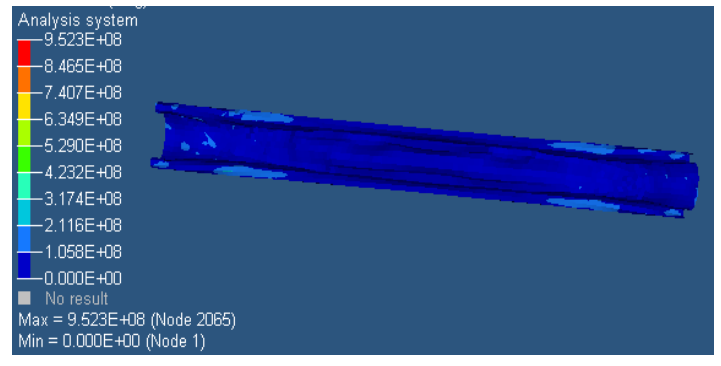

f. End of the Collision Bumper Acceleration

Figure 3. The Change of Acceleration of A a-class car in Collision 
Figure 4 is bumper in the process of collision velocity contours of about $13.8 \mathrm{~m} / \mathrm{s}$ insurance before the collision speed, that is, about $50 \mathrm{~km} / \mathrm{h}$ speed. After contact with rigid wall bumper parts start to reduce speed, as speed collision process of the lower area began to spread, and speed tends to zero. In the process of the collision, bumper part positive curved surface with the result of maximum speed, reached $21.9 \mathrm{~m} / \mathrm{s}$. So the acceleration region is the largest also, in step with acceleration of the above cloud consistent results.

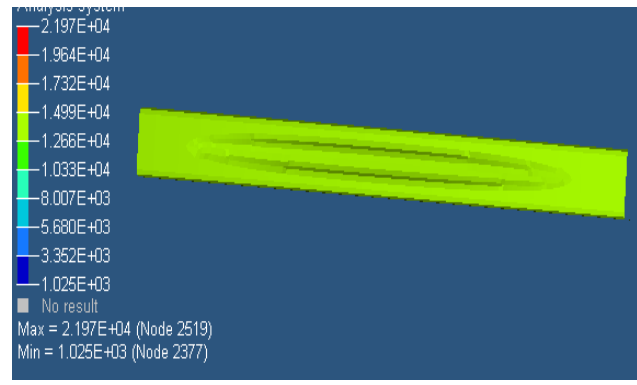

a. Before the Collision Bumper Speed Nephogram

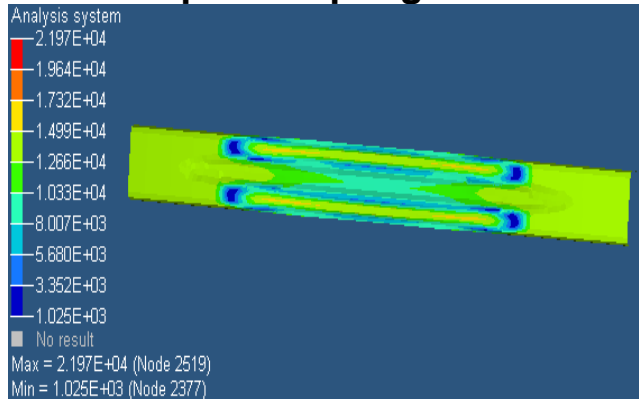

\section{c. Bumper Speed Nephogram in} Collision $\mathrm{t}=4 \mathrm{~ms}$

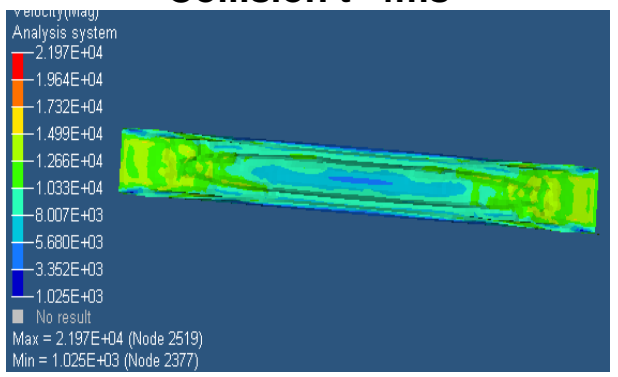

\section{e. Bumper speed nephogram in Collision $\mathrm{t}=6 \mathrm{~ms}$}

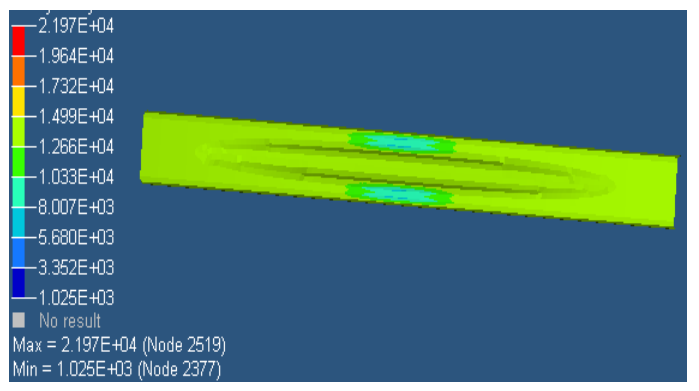

b. Collision Bumper Speed Nephogram $\mathrm{t}=3 \mathrm{~ms}$

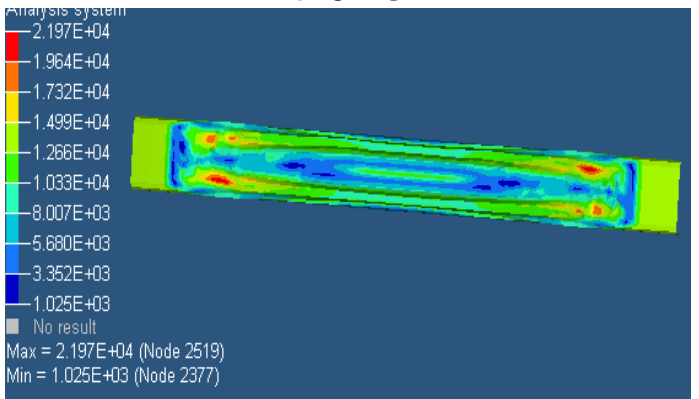

\section{d. Bumper Speed Nephogram in} Collision $\mathrm{t}=5 \mathrm{~ms}$

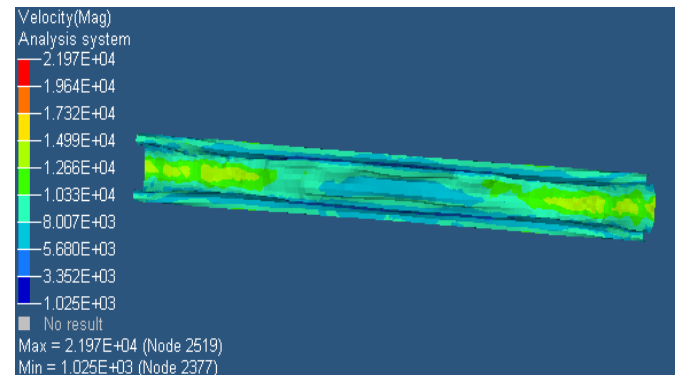

f. End of the Collision Bumper Speed Nephogram

Figuer 4. The Change of Speed of A a-class Car in Collision

\subsection{The Bumper is Curve Analysis}

Figure 5 is a bumper in the process of collision speed curve, bumper without contact with rigid wall is to keep the speed of $13.8 \mathrm{~m} / \mathrm{s}$, but the contact accumed began to decline, until the velocity to zero. And then by rigidity wall back, speed rise again. Figure 6 is a bumper in the process of collision energy absorption, as shown in figure bumper without collision, energy 
obsoupeion not happen. After contact with the rigid wall began to absorb collision energy, the energy absorption process with an ongoing process of collision.

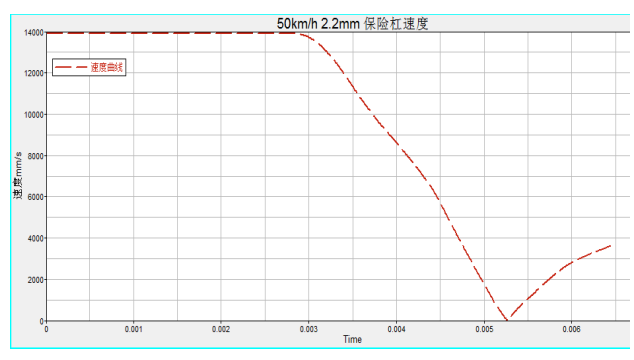

Figure 5. Bumper Speed Curve

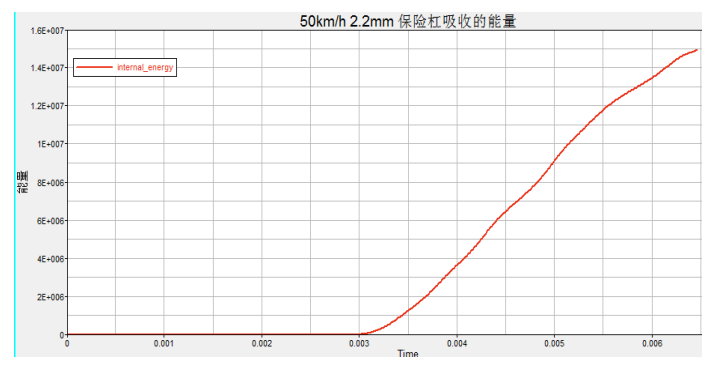

Figure 6. Bumper Energy Absorption

\subsection{Bumper Optimize}

The key point of Bumper optimized is that how to find a balance point between bumper quality and weight. Optimization scheme will thicken the bumper thickness of $2.2 \mathrm{~mm}$ to 4 $\mathrm{mm}$, Recarry on the finite element analysis and solving. And compare the two kinds of thickness under the speed, acceleration and energy absorption of collision performance parameters, analysis of bumper thickening effect on safety performance in the future. Figure 7 and figure 9 respectively two kinds of thickness of bumper acceleration curves and their respective accelerate cloud picture, $2.2 \mathrm{~mm}$ thick bumper maximum speed is about $97 \mathrm{~g}, 4$ $\mathrm{mm}$ thick bumper maximum acceleration is about $65 \mathrm{~g}$, maximum acceleration reduced about $32 \%$ after thickness increases.

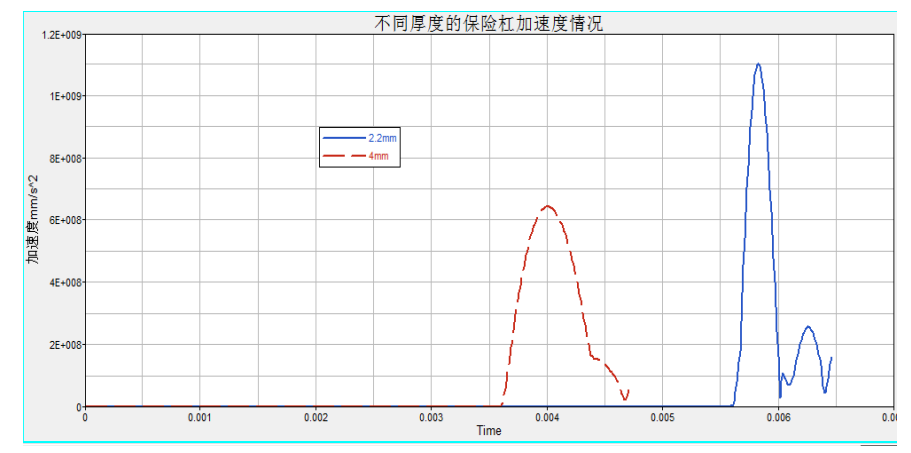

Figure 7. Acceleration Curve of Different Thickness Bumpers

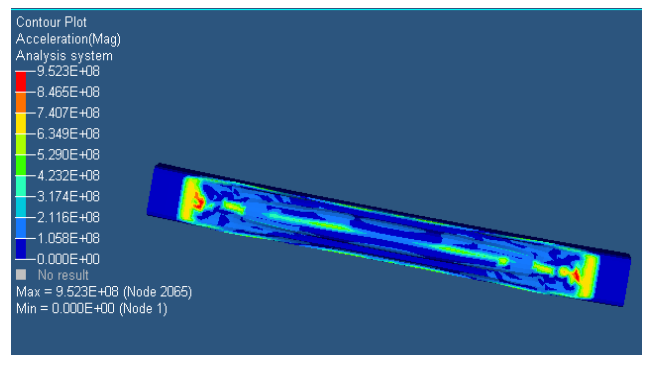

Figure 8. Acceleration of Bumper of $2.2 \mathrm{~mm}$ Thick

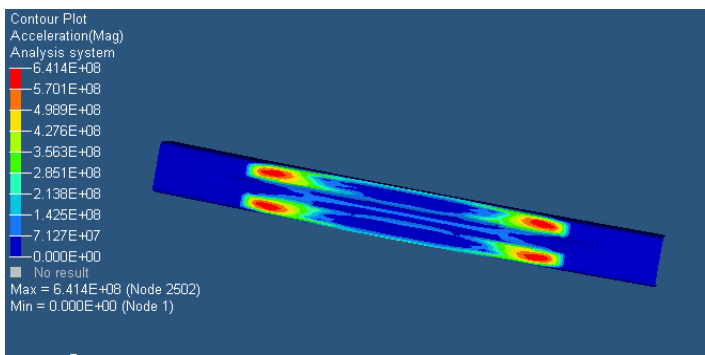

Figure 9. Acceleration of Bumper of 4 mm Thick 
According to the above conclusion, thickening bumper thickness indeed can improve security. In order to further confirm the conclusion, the following step would change the standard, using the European E.C.E R42 low-speed collision test standard, the standard of collision speed is $4 \mathrm{~km} / \mathrm{h}$, use the main purpose of using this standard is to observe bumper thickening performance in different speed of collision.

Figure 10 to figure 12 is a low-speed acceleration situation of case bumpers, when the thickness of bumper is $2.2 \mathrm{~mm}$ when the maximum acceleration of $4.9 \mathrm{~g}$, bumper thickness increased to $4 \mathrm{~mm}$ when the maximum acceleration is around $4.2 \mathrm{~g}$, the maximum acceleration decreases by about $14.2 \%$.

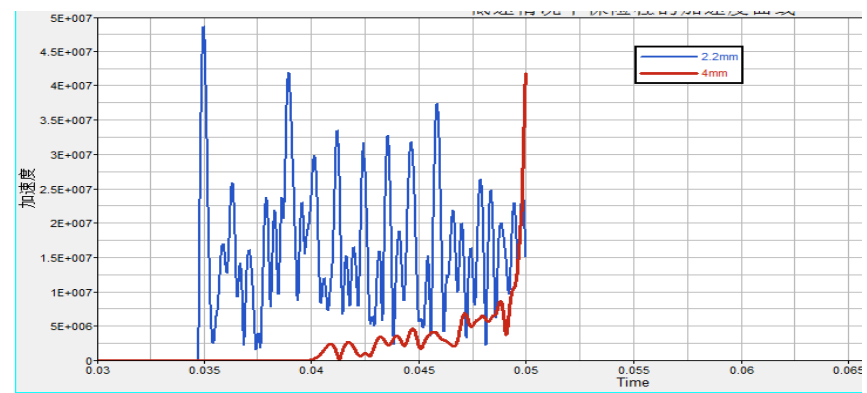

Figure 10. Speed Acceleration Curve of the Bumper of Two Thickness

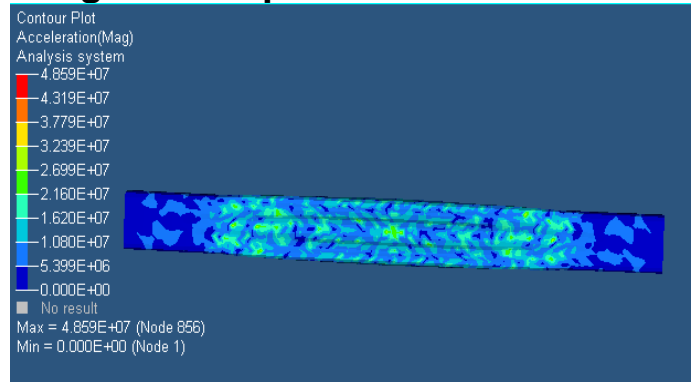

Figure 11. 4km/h 2.2mm Bumper Acceleration

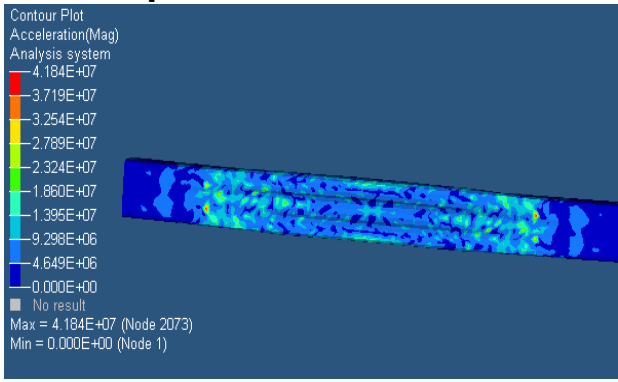

Figure 12. 4km/h 4mm Bumper Acceleration

Bumper Figure 13 for low speed under the condition of two kinds of thickness of energy absorption, can be found by comparing the curve, the thickness is $4 \mathrm{~mm}$ of the bumper can absorb more energy than bumper thickness is $2.2 \mathrm{~mm}$, and the added value of about $50 \%$. Combined with C - NCAP standards can be concluded that thicken the thickness of the bumper real can through reduce the maximum acceleration and improve energy absorption so as to improve the safety of vehicles, and under the condition of high speed decreases due to increase the thickness of the acceleration of a maximum of $32 \%$, and decrease the maximum acceleration under the condition of low speed is $14.2 \%$, it is obviously that increase bumper thickness to improve the safety performance is more significant in high speed condition.

Change the bumper thickness to $3 \mathrm{~mm}$ retest to test and compared with $4 \mathrm{~mm}, 2.2 \mathrm{~mm}$ of the bumper, is the method of trying to find safety and bumper weight balance point.

Figure 14 is $3 \mathrm{~mm}$ thick bumper cloud picture of acceleration and the maximum acceleration is around $83 \mathrm{~g}$. In the middle of $2.2 \mathrm{~mm}$ thick bumper than maximum speed $97 \mathrm{~g}$ and $65 \mathrm{~g}$ of $4 \mathrm{~mm}$ thick bumper maximum acceleration.

Figure 15 for the thickness of the three kinds of bumper acceleration curve, three curve is in step with acceleration cloud picture results, namely the bumper maximum acceleration value of $2.2 \mathrm{~mm}, 3 \mathrm{~mm}$ of the bumper second, bumper maximum acceleration minimum of 4 
$\mathrm{mm}$. It can be concluded that the bumper of the maximum acceleration decreases with the increase of thickness, the safety as the thickness increases.

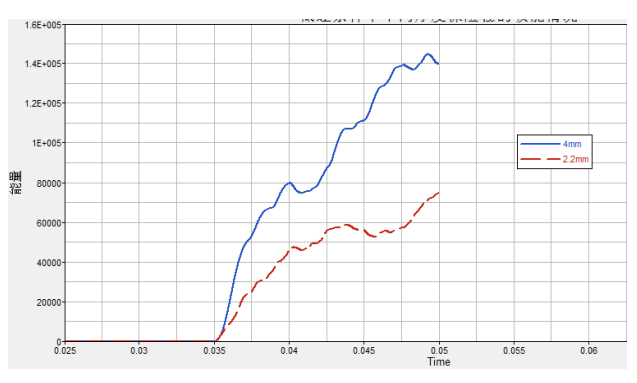

Figure 13. Energy Absorption Under the Condition Low of Speed Different Thickness Bumper

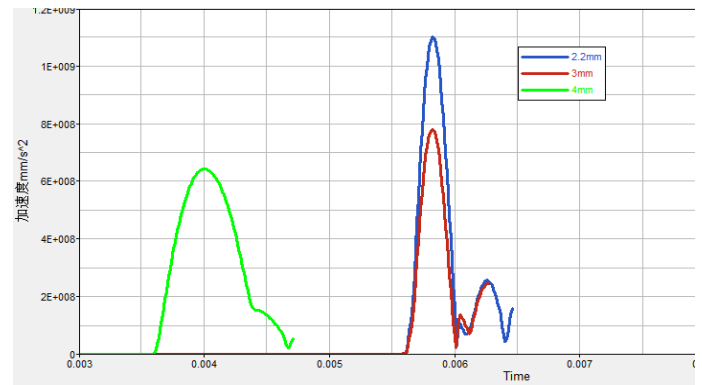

Figure 15. Acceleration Curve of the Bumper of Three Bumper of Three Absorption of Three Kinds of Different Thickness

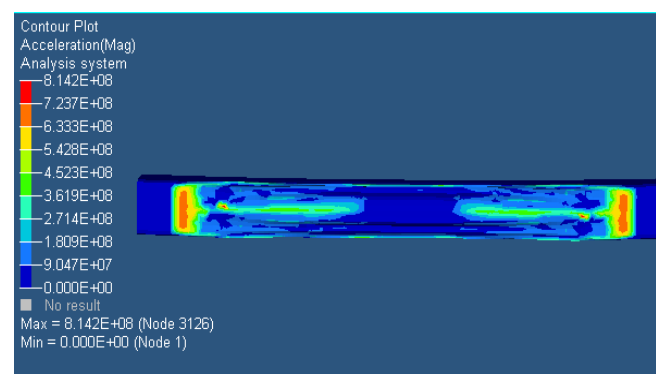

Figure 14 Acceleration of Bumper of $3 \mathrm{~mm}$ Thick

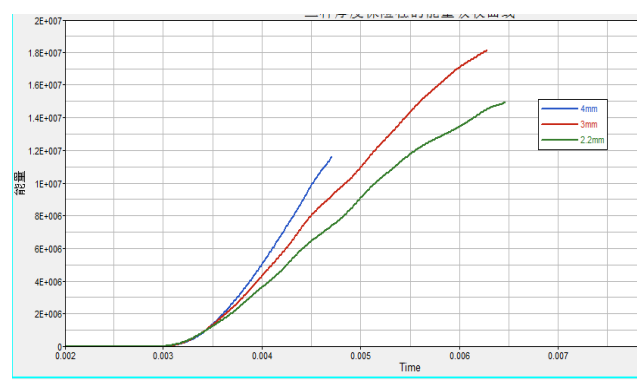

Figure 16. Curve of Energy Thickness bumper

Figure 16 for the thickness of the three kinds of bumper curve of energy absorption, at the same time bumper to absorb energy up to $4 \mathrm{~mm}, 3 \mathrm{~mm}$ of the bumper second, bumper absorbs the energy of $2.2 \mathrm{~mm}$ minimum.

By comparing three kinds of different thickness bumpers have reached that the maximum acceleration decreases with the increase of thickness, absorption of energy increases with the increase of the thickness of the law. Next to comparing the increased weight of three kinds of bumper thickness. Calculation results show that the $2.2 \mathrm{~mm}$ bumper weight about $4.7 \mathrm{~kg}, 3$ mm of bumper weight about $6.5 \mathrm{~kg}, 4 \mathrm{~mm}$ bumper weight about $8.7 \mathrm{~kg}$, as shown in Table 2 .

Table 2. Comparison of Quality and Safety Performance of Three Kinds of Thickness Bumper

\begin{tabular}{lccc}
\hline $\begin{array}{l}\text { Bumper } \\
\text { thickness }\end{array}$ & quality & $\begin{array}{c}\text { accelerati } \\
\text { on }\end{array}$ & Safety performance improvement \\
\hline $2.2 \mathrm{~mm}$ & $4.7 \mathrm{~kg}$ & $97 \mathrm{G}$ & \\
$3 \mathrm{~mm}$ & $6.5 \mathrm{~kg}$ (increase $38 \%)$ & $83 \mathrm{G}$ & Maximum acceleration value reduced $14.4 \%$ \\
$4 \mathrm{~mm}$ & $8.7 \mathrm{~kg}$ (increase $87 \%)$ & $65 \mathrm{G}$ & Maximum acceleration value reduced $34 \%$ \\
\hline
\end{tabular}


By calculating we can see that $3 \mathrm{~mm}$ of bumper weight increased $38 \%$ compared with the original bumper, maximum acceleration decreases by $14.4 \% .4 \mathrm{~mm}$ bumper weight increased $87 \%$ compared with the original bumper, maximum acceleration decreases by $34 \%$. After comparison found that $4 \mathrm{~mm}$ bumper while better in improving safety and the increase in weight is too big, do not suitable for the concept of energy conservation and environmental protection.

\section{Conclusions}

Summing up the above research the authors carried out their own comparison between the lower. For bumper collision simulation, the finite element method is very suitable. After analyzing the result of the finite element calculation results and optimization can get the following conclusion:

(1) The smaller the maximum acceleration of collision bumper, the smaller the discrete degree of vehicle and the safety performance is higher.

(2) If the collision bumper absorbs more energy in the process, of bumper safety is higher.

(3) The bumper bar iron metal thickness increase weight increased by $87 \%$ for $4 \mathrm{~mm}$ and the safety performance increased by $34 \%$. Increased to $3 \mathrm{~mm}$ thickness, the weight increase $38 \%$ and the safety performance increased by $14.4 \%$.

(4) The bumper bar iron metal thickness is increased to $3 \mathrm{~mm}$, weight increase and to improve the performance of security is a balance point.

\section{References}

[1] B. Bartczak, D. Gierczycka-Zbrozek, Z. Gronostajski, S. Polak and A. Tobota, "The use of thin-walled sections for energy absorbing components: a review", Archives of Civil and Mechanical Engineering, vol. 10, no. 4, (2010), pp. 5-19.

[2] ARUP: A New Pedestrian Lower Legform Model for LS-DYNA, ARUP, (2003).

[3] L. Aktay, A. to F. Johnson and M. Holzapfel, "Prediction of impact damage on sandwich composite panels", Journal of Computational materials science, vol. 32, no. 3, (2005), pp. 252-260.

[4] Q. Li Cheng, W. Xiu Chun and W. Chao, "Car crash worthiness offset collision simulation analysis", Journal of liaoning institute of technology, vol. 26, no. 4, (2006), pp. 252-254.

[5] K. J. Kim and S. T. Won, "Effect of structural variables on automotive body bumper impact beams", International J Automotive Technology, vol. 9, no. 6, (2008), pp. 713-717.

[6] S. Palanivelu, W. Van Paepegem, J. Degrieck, D. Kakogiannis, J. Van Ackeren and D. Van Hemelrijck, "Parametric study of crushing parameters and failure patterns of pultruded composite tubes using cohesive elements and seam", Part I: Central delimitation and triggering modeling, 29 20109(29), pp. 729-741.

[7] J. Huang, Y. Xia, B. Nie and Q. Zhou, "A bumper model with dynamic contact stiffness for simulations of pedestrian legform impacts", Proceedings of the Institution of Mechanical Engineers, Part D: Journal of Automobile Engineering, vol. 227, no. 6, (2013) June, pp. 905-913.

[8] R. S. Ali Sidhu Aidy and M. R. Hassan, "Experimental determination of fatigue life of automotive jounce bumper Key Engineering Materials", Fracture and Strength of Solids VII, vol. 462-463, (2011), pp. 634-638.

[9] F.-K. Chen and S.-W. Liu, "Die compensation design for stamping a high strength automotive bumper inner", Advanced Materials Research, Advances in Manufacturing Science and Engineering, vol. 712-715, (2013), pp. 796-799.

[10] S. Wu, H. Liu and $\mathrm{H}$. Wu, "Haitao Analysis of effect of process parameters on warpage of a automobile bumper injection molded parts", Advanced Materials Research, Advances in Materials and Materials Processing, vol. 652-654, (2013), pp. 2062-2066.

[11] M. M. Rimy and A. A. Faieza, "Simulation of car bumper material using finite element analysis", Journal of Software Engineering, vol. 4, no. 3, (2010), pp. 257-264. 